\title{
The Benefits of the Plastination Techniques for the Anatomo Clinical Studies of Ankle J oint Ligaments Injuries
}

\author{
ALINA MARIA SISU ${ }^{1}$, GHEORGHE NODITI2*, DAN GRIGORESCU3*, SORIN FLORESCU4, JENEL MARIAN PATRASCU4, \\ JENEL MARIAN PATRASCU J R. ${ }^{5 *}$, ELENA POP', SORIN LUCIAN BOLINTINEANU ${ }^{1}$ \\ ${ }^{1}$ Victor Babes University of Medicine and Pharmacy, Department of Anatomy and Embryology, 2 Eftimie Murgu Sq., 3000041, \\ Timisoara, Romania \\ ${ }^{2}$ Victor Babes University of Medicine and Pharmacy, Department of Plastic Surgery, 2 Eftimie Murgu Sq., 3000041, Timisoara, \\ Romania \\ ${ }^{3}$ Transilvania University, Faculty de Medicine, 29 Eroilor Blvd., 500036, Brasov, Romania \\ 4. Victor Babes University of Medicine and Pharmacy, Department of Orthopaedics and Traumatology II, 2 Eftimie Murgu Sq., \\ 3000041, Timisoara, Romania \\ 5. Victor Babes University of Medicine and Pharmacy, 2 Eftimie Murgu Sq., 3000041, Timisoara, Romania
}

The present research was made by following three directions: dissection and plastination, clinical ankle joint ligament injuries and MRI and CT examination of the cases.191 cases of ankle joint ligament injuries have been studied during two years. They were examined clinically and radiologically, using CT and MRI testing. The classification of ankle sprain was based on the number of injured ligaments. Out of the 191 cases diagnosed with ligament injuries, 92 involved the anterior talofibular ligament, 54 in the calcaneofibular ligament, 40 involved the posterior talofibular ligament and 5 involved the deltoid ligament. First degree sprain involves the injury of the anterior talofibular ligament, the second degree sprain involves the injury of the anterior talofibular ligament and of the calcaneofibular ligament, and the third degree sprain involves the damaging of anterior and posterior talofibular ligaments, as well as the calcaneofibular ligament. In this paper we have diagnosed a number of 39 first degree springs, 12 of second degree springs and 41 of third degree springs. The standard $X$ - ray examinations have a low diagnostic rate of the ankle ligament injuries. Conventional MRI has a higher accuracy in diagnosing ankle joint collateral ligaments lesions.

Keywords: MRI, ligaments, ankle joints, S10 Biodur technique

Ankle joint has three ligament groups:

The syndesmotic ligament unit, made up from: the anterior tibiofibular ligament, the posterior tibiofibular ligament and the interosseous ligament [1-3, 31, 34].

The lateral collateral ligaments made up from: the anterior talofibular ligament, the posterior talofibular ligament and the calcaneofibular ligament.

The deltoid ligament, consisting of four components: the anterior tibiotalar ligament; the posterior tibiocalcaneal ligament and the tibionavicular ligament.

Plastination is a sustainable method of conservation, in which dissected anatomical parts are impregnated with silicone, making a teaching material, with prolonged time usage. S3, S6 and S10 are the most commonly used agents for tissue plastination. Using these methods of preservation, it can be achieved removal of formaldehyde as a means of permanent preservation, including the parts of specimens that are important in clinics like injuries in ortopaedics or different types of tumours. Anatomic/ pathologic preparations thus obtained are handled and stored under favourable conditions. Substances used for plastination are less toxic or nontoxic. Unless the formaldehide, they make the pieces durable, easy handled and very accurate $[4-7,32]$.

\section{Experimental part}

Material and methods

The present research was made by following three directions: dissection and plastination, clinical

ankle joint ligament injuries and MRI and CT examination of the cases. A number of 191 cases of ankle joint ligament injuries have been studied over a period of two years, between March, 2013 and February, 2015. They were examined clinically and radiological, using CT and MRI. The standard $X$ - ray examination, using classical positioning, was the first choice in the investigation. The result obtained after the interpretation of the X- ray examination led to a first evaluations and the decision was made regarding the first steps or the necessity for additional imaging investigations. Also, plastination technique using Biodur S10 is necessary for preservation of some ankle joints, in order to understand the structures involved in possible injuries at this level.

CT examination offered the possibility of a thorough analysis of ankle joint in all cases. It was completed according to a technique of data gathering using unenhanced axial sections, top bottom, $10 \mathrm{~mm}$ slice thickness and $10 \mathrm{~mm}$ inter slice thickness, the patient lying in prone or supine position. The ankle ligaments are like some low signal linear thin strips, adjacent to bones and surrounded by high signal fatty subcutaneous tissue.

In order to see all ligaments MRI examination is recommended, using axial or coronal sections, the foot in dorsiflexion position [31]. The anterior and the posterior tibiofibular ligaments can be visualized in at least two axial and coronal sequences, at the level of the talar dome. The anterior and posterior talofibular ligaments are usually highlighted on a single axial section, distal to the tibiofibular ligaments. The anterior talofibular ligament is highlighted as a low signal linear stripe which stretches from the talus to the fibular malleolus. The posterior talofibular ligament is in the shape of a teardrop stretches from the talus to the distal epiphysis of fibula. Most frequently, the calcaneofibular ligament is like a low linear stripe parallel to the lateral wall of the calcaneus. This ligament is best visualized on coronal sections where it shows like low

*email: dr.noditi@gmail.com; Phone: 0722356230; dan_o_grigorescu_@yahoo.com,Phone: 0740133345 ; patrascujenel@yahoo.com 
signal intensity round and homogeneous structure which can be traced back from the fibular origin to the calcaneal insertion. Many folded components of the deltoid ligament can be well visualized both on coronal sections and axial sections. The deep tibiotalar component of this ligament normally presents regular striated appearance, giving it a heterogeneous aspect. The MRI examinations were performed using a 1.5 Tesla GE scanner with a standard protocol which included spin-echo sequence in multiple incidences: sagittal and coronal T1, Axial T2 and T1 spinecho, both unenhanced and enhanced.

\section{Results and discussions}

The injuries of the collateral ligament of the ankle range between 15 and $22 \%$ of the total injuries of the athletes (fig. 1). The anterior talofibular ligament is the weakest and therefore it is most often affected. The next affected ligaments, according to their frequency, are the calcaneofibular ligament and the posterior talofibular ligament.
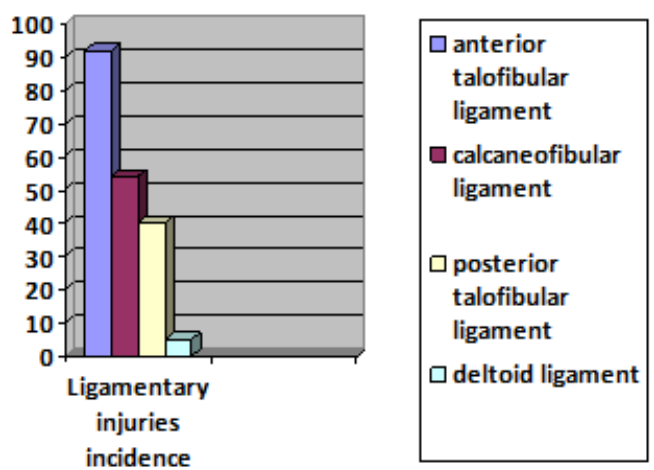

Fig. 1. Incidence of ligamentary injuries

The ranking of ankle sprain is according to the number of affected ligaments:

- the first degree sprain means partial or total injury of the anterior talofibular ligament;

- the second degree sprain is characterized by the partial or total injury of the anterior talofibular ligament and the calcaneofibular ligament;

- the third degree sprain is characterize by the partial or total injury of the talofibular previously calcaneofibular ligament and the posterior ligament talofibular.

The most important chemical agents used for hardening and finishing the specimens preservation are rubbersilicones $[30,33,34]$. The last used and the most important, is hardener Biodur 56.

We have produced plastinated structures like entire brains, cerebral hemispheres, livers, upper limbs, lower limbs, joints. On their surfaces structures like tendons, nerves, vessels, gyri, sulci, can be seen, palpated, and measured at their real dimensions. Also the ankle joint ligaments are very accurate in case of sprain or complete damage $[8,9]$. The major advantages of Moor LDLS (laser Doppler line scanner) are the fact that there is no need for direct contact with the tissue (max. distance $19 \mathrm{~cm}$ ), the possibility to accomplish multiple measurements allowing to obtaining many images in the area of interest (120 pixel/cm) and most importantly it allows a global analysis of blood flow in the area of interest being a practical alternative to more complex and invasive monitoring techniques. This technique has been shown to be easy to learn by surgeons [10].

Since the surgical treatment of acute ligament injuries of the ankle is rare, MRI study of the ankle joint ligaments is more useful in diagnosing the patients with a history of chronic instability of the ankle joint. The chronic injury of the ankle joints is obvious under the form of some thickenings, thinning, elongation or irregular modifications of the ligament contour. Decreasing in the intensity of the signal at the level of peri articular fat may indicate some synovial proliferation. Out of the 191 cases of ligament injuries diagnosed, 92 were related to the anterior talofibular ligament, 54 to the calcaneofibular ligament, 40 to the posterior talofibular ligament,and 5 were injuries of the deltoid ligament [11-14].

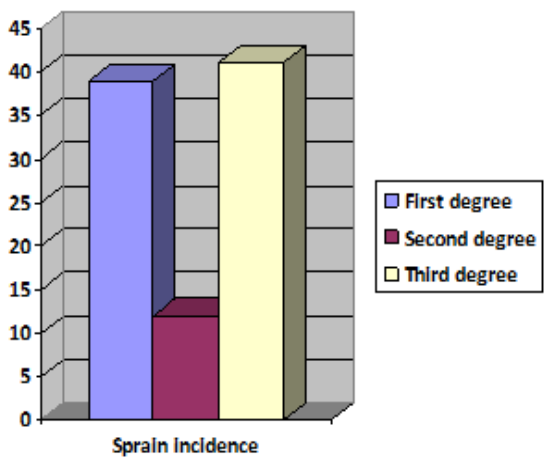

Fig. 2. Sprain incidence

The first degree sprain involves the injury of the anterior talofibular ligament, the second degree sprain involves the injury of the anterior talofibular ligament and of the calcaneofibular ligament, while the third degree spring involves the injury of the anterior and posterior talofibular ligaments, as well as calcaneofibular ligament (fig. 2). In the present study we have diagnosed a number of 39 first degree sprains, $12 \mathrm{~s}$ degree sprains, and 41 third degree sprains [15-19].

Out of the 191 cases with ligament injuries diagnosed, a number of 48 cases were recurrent (fig. 3 ) as follows: 31 of the anterior talofibular ligament; 11 of the calcaneofibular ligamen; 6 of the posterior talofibular ligament.
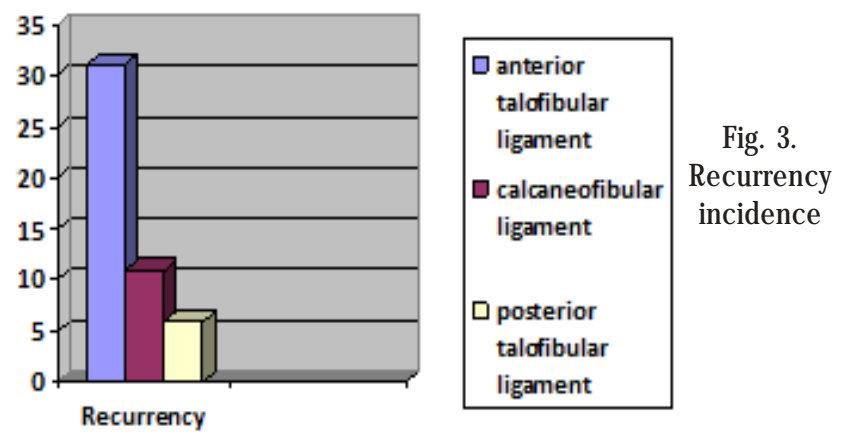

The injuries of the calcaneofibular ligament (fig. 4) can be detected on a routine axial scan of the ankle joints, but can be better visualised on coronal sections. The normal calcaneofibular ligament is highlighted as a low intensity, homogenous, strip, surrounded by fat.

The injured calcaneofibular ligament (fig. 5) is highlighted as being thickened, heterogeneous and surrounded by obliterating fat [20-22].

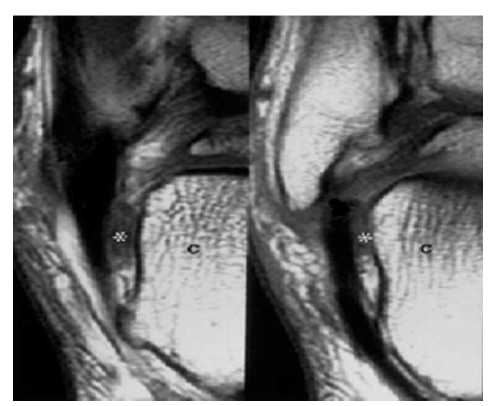

Fig. 4. Injuried calcaneofibular ligament. MRI coronal section. A thickened ligament can be seen $(*)$ located towards the lateral wall of the calcaneus (c) 


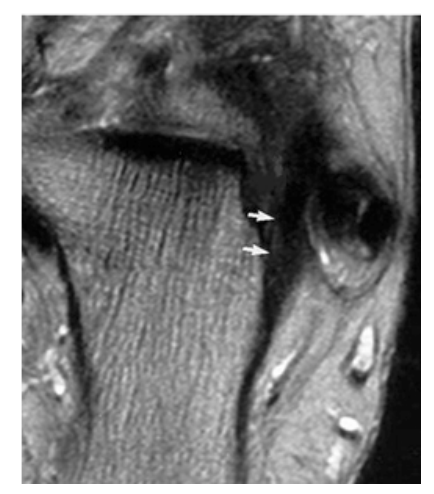

Fig. 5. Chronic injury of the calcaneofibular. MRI axial section. Thickenings and unevenness of the calcaneofibular ligament (arrows) can be noticed

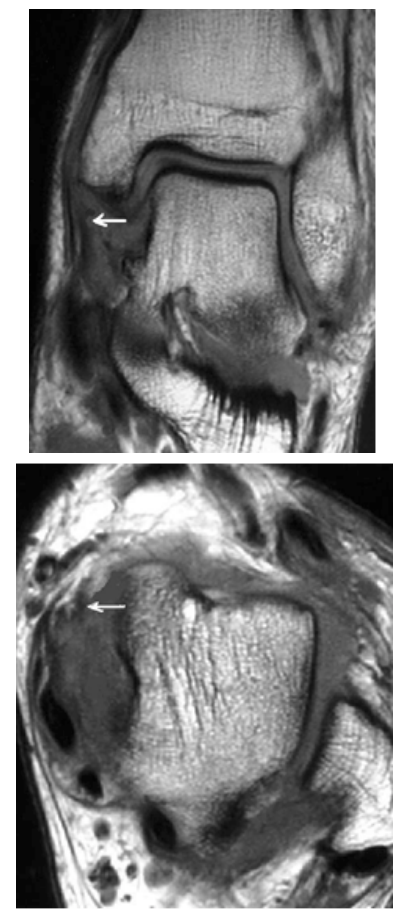

Fig. 6. Deltoid ligament injury caused by the loss of striation regularities .MRI coronal section.

Fig. 7. Injury of the deltoid ligament highlighted by the loss of striation regularity. The arrow indicates the presence of some fibers of the tibionavicular ligament. MRI axial section.

The MRI studies show that the injuries of the deltoid ligament, and especially of its tibiotalar component, are usually associated with sprains caused by a forced inversion of the ankle (fig. 6). These injuries are seen as a loss of the as a loss of ligament striation regularities (fig. 7).

The accuracy of MRI scan in identifying the injuries of the collateral ligament has not been clearly established yet. The accuracy of 3D MRI in detecting the injuries of the talofibular and calcaneofibular joint injuries is around $95 \%$. MRI arthrography has an accuracy of $100 \%$, and specificity of $84 \%$ respectively, in highlighting the chronic lesions of the anterior talofibular ligament and calcaneofibular ligament unlike the conventional MRI, which has an accuracy of $59 \%$ in diagnosing chronic lesions of the collateral ligament of the ankle joint [23,24]. Plastination technique using Biodur S10 for preservation of some ankle joints, in order to understand the structures involved in possible injuries at this level are seen in figures 8, 9, 10.

\section{Conclusions}

The pathology of the ankle joint ligaments joint is rather frequent, as in 191 cases have been diagnosed, irrespective the cases of athletes which were not considered in the present study.

Most frequently the anterior talofibular ligamenthas been affected - 92 cases, followed by the calcaneofibular ligament - 54 cases, the posterior tal ofibular ligament - 40 cases and the deltoid ligament - 5 cases $[25,26]$.
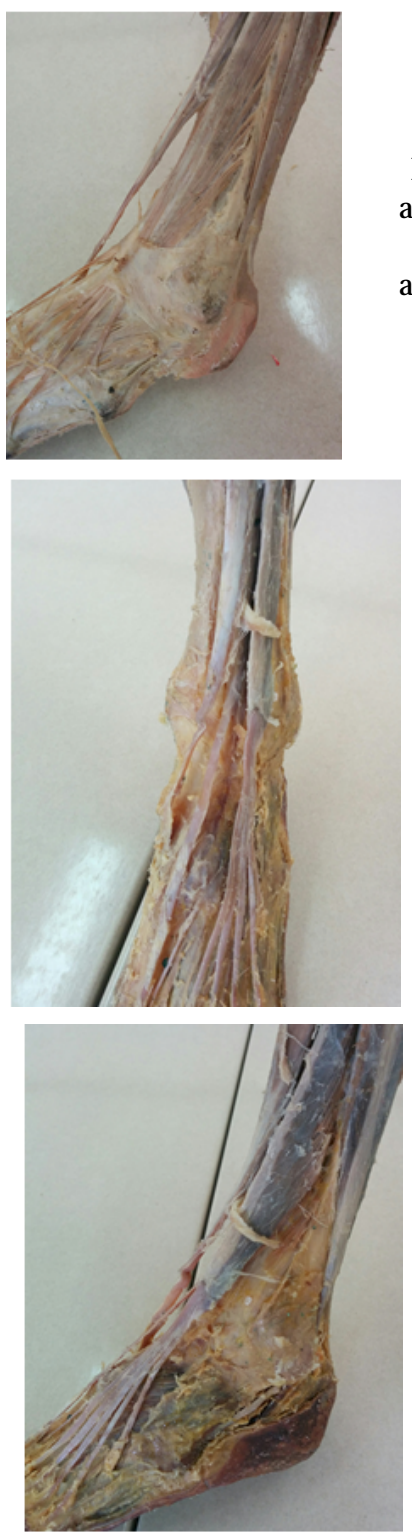

Deltoid ligament injuries have been associated each time with other ligament injuries, which accompanied them [27-29].

The most frequent sprains injuries were those of the third degree, present in 41 cases and involving the damage of all the three ligaments (anterior and posterior tal ofibular and calcaneofibular).

Standard X -ray investigations have a low rate of diagnosing the injuries of ankle joint ligaments.

Conventional MRI has an increased accuracy in diagnosing the injuries of the collateral ligaments of the ankle joint.

Out of the 191 diagnosed cases of ligament injuries diagnosed, 48 cases were recurrent ones.

Two patients had ankle joint recurrence, which may lead the diagnosis toward chronically ligament injuries.

The computerized reconstruction of plastinated ankle joints has proven useful for medical specialists such as, traumatologists, ortopaedic surgeons, and radiologists.

\section{Refrerences}

1. MULHE C, FRANK LR, RAND T, LEEREN YEH, ERIC C. WONG EC, SKAF A, DANTAS RWM, PARVIZ HAGHIGHI, DEBRA TRUDELL, RESNICK,D. Collateral ligaments of the ankle: high resolution MR imaging with a local gradient coil and anatomic correlation in cadavers. SCIENTIFIC EXHIBIT RadioGraphics 1999; volume 19, pp: 673-683.

2. MESGARZADEH M, SCHNECK CD, TEHRANZADEH J, CHANDNANI VP, BONAKDARPOUR A. Magnetic resonance imaging of the ankle 
ligaments: emphasis on anatomy and injuries to lateral collateral ligaments. Magn Reson Imaging Clin N Am 1994; no 2, pp: 39-58. 3. VERHAVEN EF, SHAHABPOUR M, HANDELBERG FW, VAES PH, OPDECAM PH. The accuracy of three-dimensional magnetic resonance imaging in the diagnosis of ruptures of the lateral ligaments of the ankle. Am J Sports Med 1991; volume 19, pp: 583-587.

4. OTTONE, N,E, CIRIGLIANO, V, BIANCHI, H,F, MEDAN, C,D, ALGIERI, $R, D, B O R G E S, B R U M, G, F U E N T E S, R$, New Contributions to the Development of a Plastination Technique at Room Temperature with Silicone, Anat Sci Int. Mar; 90, N0.2, 2015,p.126-135.

5. VON HAGENS, G. - Curing with the S10Standard Technique, Technical leaflet. Anatomisches Institut 1, Universtat Heidelberg, 1984.

6. MAHAJAN, A, AGARWAL, S, TIWARI, S, VASUDEVA, N. Plastination: An Innovative Method of Preservation of Dead Body for Teaching and Learning Anatomy. MAMC J Med Sci ,NO. 2, 2016, p .38-42.

7. PENTEA, M., HULEA, C., STANCU, A., BUTNARIU, M., CRISTINA ,R. T., Developing the Plastination Laboratory for the Technique S10, Mat Plast., 53, no.1 2016, p.150

8. BICKLEY, H,C, ; VON HAGENS, G ; TOW NSEND, F,M, - An Improved Method for the Preservation of Teaching Specimens, Arch Path Lab Med., 105, 1981, p. 674.

9. VON HAGENS G. Heidelberg Plastination Folder: Collection of Technical Leaflets for Plastination. 2nd ed. Heidelberg: Anatomische Institut, Universitat; no. 2, 1986, p.1-6; 3, 1986, p.1-13; 4, 1986, p.1-20; 5, 1986, p.1-17.

10. NODIT,I GH., TODEA, C.,Laser Doppler Imaging - as a Non-invasive Method for Assesing Regional Microcirculation when using Plastic Materials for Guided Healing, Mat. Plast., 50, no.1, 2013, p.40 11. BELTRAN J, ROSENBERG ZS. Ankle and foot. In: Stark DD, Bradley WG, eds. Magnetic resonance imaging. 3rd ed. St Louis, Mo: MosbyYear Book, 1999; 873-929.

12. KLEIN MA. MR imaging of the ankle: normal and abnormal findings in the medial collateral ligament. AJR Am J Roentgenol 1994; volume 162 , no 2, pp:377-383.

13. CHANDNANI, VP, HARPER, MT, FICKE, JR, GAGLIARDI, JA, ROLLING, L, CHRISTENSEN, KP, AND HANSEN, MF. Chronic ankle instability: evaluation with MR arthrography, MR imaging, and stress radiography. Radiology. 1994; volume 192, pp :189-194.

14. LIU, S.H., RASKIN, A., OSTI, L., BABER, C., JACOBSON, K., FINERMAN, G. Arthroscopic treatment of anterolateral ankle impingement. Arthroscopy. Arthroscopy 1994; volume 10:215-218.

15. RUBIN DA, TISHKOFF NW, BRITTON CA, CONTI SF, TOWERS J D. Anterolateral soft-tissue impingement in the ankle: diagnosis using MR imaging. AJ R Am J Roentgenol 1997; volume 169:829-835.

16. FAROOKI S, YAO L, SEEGER LI. Anterolateral impingement of the ankle: effectiveness of MR imaging. Radiology 1998; volume 207:357360.

17. JORDAN LK, HELMS CA, COOPERMAN AE, SPEER KP. Magnetic resonance imaging findings in anterolateral impingement of the ankle. Skeletal Radiol 2000; volume 29:34-39.

18. KLEIN MA, SPREITZER AM. MR imaging of the tarsal sinus and canal: normal anatomy, pathologic findings and features of the sinus tarsi syndrome. Radiology 1993; volume 185:233-240.

19. BELTRAN J. Sinus tarsi syndrome. Magn Reson Imaging Clin N Am 1994; volume 2:59-65.
20. ERICKSON SJ, COX IH, HYDE J S, CARRERA GF, STRANDT JA, ESTKOWSKI LD. Effect of tendon orientation on MR imaging signal intensity: a manifestation of the magic angle phenomenon. Radiology 1991; volume 181:389-392.

21. ROSENBERG ZS, MELLADO J, BENCARDINO J. Normal variants and pitfalls in magnetic resonance imaging of the foot and ankle. In: Shirkhoda A, eds. Normal variations and diagnostic pitfalls in sectional body imaging. Baltimore, Md: Williams \& Wilkins, 1999; pp: 641-659. 22. TREVINO S, BAUMHAUER JF. Tendon injuries of the foot and ankle. Clin Sports Med 1992; volume 11:727-739.

23. WEINSTABI R, STISKAL ZM, NEUHOLD A, AAMLID B, HERTZ H. Classifying calcaneal tendon injury according to MRI findings. J Bone J oint Surg [Br] 1991; volume 73:683-685.

24. CHANDNANI VP, BRADLEY YC. Achilles tendon and miscellaneous tendon lesions. Magn Reson Imaging Clin N Am 1994; issue 2:89-96. 25. DILLON EH, POPE CF, BARBER V, JOKL P, LYNCH K. Achilles tendon healing: 12-month follow-up with MR imaging (abstr). Radiology 1990; volume 177, page:306.

26. NUHMANI S, KHAN MH. Lateral ankle sprain: A review. Saudi J Sports Med 2014; volume 14:14-20.

27. MIYAMOTO W, TAKAO M, YAMADA K, MATSUSHITA T. Accelerated Versus Traditional Rehabilitation After Anterior Talofibular Ligament Reconstruction for Chronic Lateral Instability of the Ankle in Athletes. Am J Sports Med. 2014; volume 42, issue 6, pp:1441-7.

28. CLANTON TO, VIENS NA, CAMPBELL KJ, LAPRADE RF, WIJ DICKS CA. Anterior talofibular ligament ruptures, part 2: biomechanical comparison of anterior talofibular ligament reconstruction using semitendinosus allografts with the intact ligament. Am J Sports Med. 2014; volume 42, issue 2, pp:412-6.

29. CAMPBELL KJ, MICHALSKI MP, WILSON KJ, GOLDSMITH MT, WIJ DICKS CA, LAPRADE RF, CLANTON TO. The ligament anatomy of the deltoid complex of the ankle: a qualitative and quantitative anatomical study. The American Journal of Bone and Joint Surgery 2014; volume 96(8):e62, doi: 10.2106/J BJ S.M.00870.

30. CAPLESCU, C.R., MARSAVINA, L., BORDEASU, I., SEKEI, R., The fracture of polyurethane materials in the presence of stress concentrators, Mat. Plast., 47, no.3,2009, p.379

31. TATU, RF., IVASCHESCU, V, HURMUZ, M., TATU, C., PUSCASIU, C D., SISU, A.,Vibration Behaviour of Bone Fractures Fixed with Biocompatible Material Plates, Mat Plast, 50, no. 4, 2013, p. 269

32. BICKLEY, H,C, Plastination: A new Technique for Anatomic Pathology and Forensic Science Pathology, Update Series, 16, NO. 1,1984, p.34-37.

33. CRAINICEANU, Z., IANES E., MATUSZ, P., BLOANCA, V., SELEACU, E., NARAD, V., NARAD, G., NODITI G., BRATU, T., Method of Titanium Plate Use for Morphological and Functional Human Face Recontruction, Mat. Plast., 53, no. 3, 2016, p. 518

34. PETRESCU, H. P.,DINU, G., NODITI, G., BERCEANU-VADUVA, M., BRATU, D.C., VERMESAN, D., Experimental morphologic and radiologic study of the integration of bone grafts into the host tissue and of the dynamics of the graft-receptor interface, ROMANIAN J OURNAL OF MORPHOLOGY AND EMBRYOLOGY, Volume: 55, Issue: 2, Supplement: S, pp: 607-612, 2014

Manuscript received: 21.03 .2017 